\title{
INTOXICAÇÃO POR 5- FLUOROURACIL EM CÃO - RELATO DE CASO
}

Nathália das Graças Dorneles Coelho¹, Paula Costa de Oliveira Pinto ${ }^{1}$, Fernanda dos Santos Alves ${ }^{2}$, Breno Curty Barbosa ${ }^{2,}$ Suzanne Lilian Beier ${ }^{3}$, Adriane Pimenta da Costa Val Bicalho ${ }^{4}$.

1 Doutoranda em Ciência animal pela Universidade Federal de Minas Gerais (UFMG), Minas Gerais-MG, Brasil.

2- Doutor em Ciência animal pela Universidade Federal de Minas Gerais (UFMG), Minas Gerais-MG, Brasil.

3- Professora Doutora do curso de Medicina Veterinária da Universidade Federal de Minas Gerais (UFMG), Minas Gerais-MG, Brasil.

4- Professora Doutora do curso de Medicina Veterinária da Universidade Federal de Minas Gerais (UFMG), Minas Gerais-MG, Brasil. E-mail: adriane@vet.ufmg.br

Recebido em: 15/05/2020 - Aprovado em: 15/06/2020 - Publicado em: 30/06/2020 DOI: 10.18677/EnciBio_2020B31

As intoxicações acidentais correspondem a uma parcela importante da casuística de urgência e emergência em cães. Possui etiologia diversa, destacando-se a ingestão de fármacos destinados para uso humano, principalmente, os indicados para aplicação tópica. O 5-Fluorouracil (5-FU) é um quimioterápico antimetabólico utilizado, comumente, em humanos, na forma de creme, para o tratamento de câncer colorretal e alguns tumores superficiais de pele. A intoxicação de cães por este composto na maioria dos casos é grave e letal. O presente trabalho visa relatar os achados clínicos, laboratoriais e o tratamento de sucesso de uma cadela que ingeriu o 5-FU em dose letal.

PALAVRA- CHAVE: canino, emergência, tratamento.

\section{INTOXICATION BY 5- FLUOROURACIL IN A DOG - CASE REPORT}

\begin{abstract}
Accidental poisoning is an important part of the urgency and emergency series in dogs. Its etiology is diverse, highlighting the intake of drugs intended for human use, especially those indicated for topical application. 5-Fluorouracil (5-FU) is an antimetabolic chemotherapy used, commonly, in humans, in the form of cream, for the treatment of colorectal cancer and some superficial skin tumors. Poisoning of dogs by this compound in most cases is severe and lethal. The present work aims to report the clinical, laboratory findings and the successful treatment of a female dog who ingested 5-FU in a lethal dose.
\end{abstract}

KEYWORDS: canine, emergency, treatment. 


\section{INTRODUÇÃO}

As intoxicações agudas por medicamentos humanos ou veterinários são comuns em animais domésticos e podem causar danos irreversíveis (GLASS et al., 2019). Apresenta etiologia diversa e dentre os fármacos potencialmente causadores de intoxicações está o 5-Fluorouracil (5-FU). O 5-FU foi sintetizado em 1957 fundamentado na biologia tumoral, sendo um potente fármaco antimetabólico. Esses agentes assemelham-se aos metabólitos naturais, porém ao incorporarem às células transmitem mensagens errôneas. Estas informações inadequadas atuam tanto no bloqueio da produção de enzimas necessárias para a formação de substâncias fundamentais, bem como na síntese de DNA ao inserir nas cadeias de RNA e/ou DNA na fase "S" de divisão celular (DIASIO; HARRIS,1989).

O 5-FU é frequentemente utilizado em medicina, na apresentação tópica, para o tratamento de pacientes portadores de alguns tumores superficiais de pele, dermatites actínicas e câncer colorretal (LONGLEY et al., 2003).Embora seja utilizado de maneira segura e tópica em um caso oftalmológico (OVERTON et al; 2015), o fármaco não é utilizado em medicina veterinária, pois a dose terapêutica (150 $\mathrm{mg} / \mathrm{m}^{2}$, aproximadamente $5 \mathrm{mg} / \mathrm{kg}$, por via-intravenosa) é muito próxima da dose tóxica, além de causar toxicidade neurológica em cães (VELÁSQUEZ et al., 2015, em linhagens celulares com alta atividade mitótica (ZHOU et al., 2017, ZHOU et al., 2018). As principais alterações clínicas observadas nas intoxicações por 5-FU estão relacionadas a injúrias gastrointestinais, cardiocirculatórias, respiratórias, neurológicas e hematopoiéticas, porém encefalites podem ser observadas (ASAD et al., 2020). Frente à variedade de sistemas acometidos, os sinais clínicos são inespecíficos e, na maioria dos casos, os pacientes cursam com óbito (SAYRE et al., 2012 VELÁSQUEZ et al., 2015, KHOO et al. 2018, ASAD et al., 2020, ROMANS et al., 2020).

Os animais domésticos podem entrar em contato com este composto a partir de qualquer utilização clínica ou pela exposição acidental (LONGLEY et al., 2003; SAYRE et al., 2012). A exposição acidental esta, via de regra, associada à mastigação de tubos contendo creme a base de 5-FU. Independentemente da causa de exposição os pacientes geralmente cursam com óbito de seis a 16 horas após a intoxicação (FRIEDENBERG et al., 2013, KHOO et al., 2018. ASAD et al., 2020).

O objetivo do presente trabalho, ao relatar um caso de sucesso no tratamento de intoxicação por 5-FU em cão, é demonstrar alguns achados clínicos e laboratoriais que podem ser encontrados nestes casos e orientar as condutas terapêuticas futuras.

\section{RELATO DE CASO}

Cão, fêmea, sem raça definida, cinco anos, e com peso de $10 \mathrm{Kg}$, foi admitida em quadro de parada cardiorrespiratória, na Unidade de Terapia Intensiva do Hospital Veterinário da Escola de Veterinária da Universidade Federal de Minas Gerais (UTI-HV-UFMG). A anamnese foi relatada a ausência de histórico de doença anterior, porém, nas últimas 24 horas, presença de hiporexia, crises convulsivas, sialorreia e vômitos.

Os tutores alegaram ter encontrado no ambiente um tubo contendo creme a base de 5-FU na concentração de $5 \%$. O tubo continha pouco menos de $10 \mathrm{~g}$ do produto, e foi encontrado mastigado pela paciente e sem conteúdo em seu interior, sendo a dose ingerida estimada de $90 \mathrm{mg} / \mathrm{kg}$. Foi administrado pelos tutores, sem orientação médico veterinária, duas cápsulas de carvão ativado e somente após inúmeras crises convulsivas foi procurado o serviço médico veterinário. 
Frente ao histórico exposto e ao quadro clínico de parada cardiorrespiratória (PCR) não assistida, iniciou-se de forma imediata o suporte básico e avançado à vida na busca por restaurar a circulação espontânea, bem como procedimentos para descontaminação.

Para tal, realizou simultaneamente a intubação orotraqueal e ventilação manual com reanimador manual (ambú) conectado ao fluxômetro para ofertar oxigênio medicinal $6 \mathrm{~L} / \mathrm{min}$. A frequência ventilatória aplicada até que 0 animal retornasse a circulação espontânea foi de $8-10 \mathrm{mpm}$ em ciclos ininterruptos de dois minutos. Por sua vez a massagem cardíaca fechada, foi realizada utilizando a bomba cardíaca em frequência de 100-120 compressões por minutos também em ciclos de dois minutos. Em associação a essas manobras foi realizado venóclise da veia cefálica e a administração de um bolus de dose alta de adrenalina $(0,1$ $\mathrm{mg} / \mathrm{kg} / \mathrm{lV}$ ).

Após os procedimentos supracitados a paciente manteve-se bradicárdica e em apneia, sendo então mantida em ventilação manual e administrado um bolus de sulfato de atropina, por via IV, na dose de $0,04 \mathrm{mg} / \mathrm{kg}$. Após essas manobras foram coletadas amostras de sangue periférico, para realização de hemograma, perfil bioquímico hepático e renal.

Quanto à desintoxicação, após a restauração da circulação espontânea, foi realizada a administração de fluidoterapia com solução cristaloide, ringer com Lactato, na forma de desafios volêmicos de $20 \mathrm{~mL} / \mathrm{kg}$ em 15 minutos. Em associação foi realizado o aquecimento controlado da paciente, mantendo a temperatura corporal no limite superior fisiológico (39-39,5ㄷ), na busca por aumentar o metabolismo hepático e também promover discreta hiperventilação. Também foram realizadas medidas de descontaminação, compostas pela lavagem gástrica e administração de carvão ativado, em dose única ( $5 \mathrm{mg} / \mathrm{kg} / \mathrm{VO})$.

Devido à manutenção do quadro de apneia, mesmo após completo restabelecimento das funções cardíacas foi informado aos tutores indicação do paciente em ventilação mecânica controlada. $O$ procedimento não foi autorizado, ainda assim, após duas horas de ventilação manual com ambú acoplado a fonte do oxigênio houve restabelecimento de movimentos respiratórios espontâneos. A paciente apresentava-se em bradpnéia e reduzida expansão de tórax e, esporádicos quadros de apneia transitória e necessitando de suporte ventilatório nesses períodos.

Durante as primeiras seis horas, após a restauração da ventilação e circulação espontâneas a cadela apresentou crises convulsivas tônico-clônicas refratárias a bolus de diazepam, $0,5 \mathrm{mg} / \mathrm{kg} / \mathrm{IV}$, optou-se pela infusão contínua chegando a taxa de $0,7 \mathrm{mg} / \mathrm{kg} / \mathrm{hora}$, sem sucesso. Frete a ausência de resposta a terapêutica a paciente foi induzida ao coma via infusão contínua de propofol na taxa, aproximada, de 0,4 mg/kg/minuto, cessando assim os movimentos tônico-clônicos.

No decorrer das 12 primeiras horas após a admissão a paciente apesar do restabelecimento das funções cardiopulmonar, apresentava-se em anisocoria e com mucosas orais cianóticas, em coma induzido pelas infusões contínuas de propofol e diazepam. Além disso, foi observada à avaliação do débito urinário médio de 4,3 $\mathrm{mL} / \mathrm{kg} /$ hora coloração turva e moderadamente avermelhada.

As reduções graduais das infusões de diazepam e propofol foram iniciadas 12 horas após a admissão, ao término das infusões a paciente se colocou em decúbito esternal e extubou espontaneamente. Desde então não sofreu novos episódios convulsivos e, horas após, a paciente estava tranquila e sem alteração em estado de consciência e clínico gerais. No obstante, após 24 horas de internação observou-se 
a presença de diarreia pastosa, discreta hiperemia de mucosas orais e vaginais, bem como inúmeras pequenas úlceras e vesículas em cavidade oral.

Frente aos achados supracitados foi acrescentado à prescrição da paciente antisséptico local, protetor de mucosas gastrointestinal (sucralfato- $50 \mathrm{mg} / \mathrm{kg} / \mathrm{VO} / 8 \mathrm{~h}$ ), antiácido (omeprazol-1,0 mg/kg/IV/12h), antiemético (cloridrato de ondansetrona $0,2 \mathrm{mg} / \mathrm{kg} / \mathrm{lV} / 8 \mathrm{~h}$ ) e analgésico (cloridrato de tramadol $-5 \mathrm{mg} / \mathrm{kg} / \mathrm{SC} / 8 \mathrm{~h}$ )

Após 72 horas da admissão a paciente obteve alta médica e foram agendados retornos clínicos a cada 48 horas. Os tutores não vieram nos retornos agendados, porém, ligaram uma semana após a alta, reportando o estado de higidez da paciente.

\section{RESULTADOS E DISCUSSÃO}

O histórico obtido à anamnese permitiu o diagnóstico conclusivo de intoxicação por 5-FU. A informação mais comumente reportada pelos tutores é a ingestão de creme a base de 5-FU, conforme observado no presente relato. Somado a isso, foi reportado informações compatíveis com crises convulsivas, vômitos e hipersalivação, sinais clínicos comuns da intoxicação por 5-FU, sendo observado em 77, 73 e 23 \% dos casos, respectivamente (DORMAN et al., 1990).

Em estudo retrospectivo com 26 casos de intoxicação acidental por 5-FU, observaram que nenhum dos 12 cães que ingeriram doses estimadas acima de 43 $\mathrm{mg} / \mathrm{kg}$ sobreviveu (DORMAN et al., 1990). No entanto, há um relato raro de um cão que ingeriu dose letal (330 mg/kg) e sobreviveu (FRIEDENBERG et al., 2013). No presente relato a cadela ingeriu uma dose estimada letal de $90 \mathrm{mg} / \mathrm{kg}$ e ainda assim apresentou um bom desfecho.

A sobrevivência dessa sem sequelas neurológicas após ingerir dose estimada de 18 vezes a terapêutica de um fármaco de alta toxicidade pode ser justificada pela administração empírica do carvão ativado pelos tutores, este que é um excelente adsorvente, contribuindo assim no processo de descontaminação (KOENIGSHOF et al., 2015). E, principalmente, pela rapidez e qualidade dos serviços de terapia intensiva prestados (FRIEDENBERG et al., 2013).

A paciente deu entrada na UTI-HV-UFMG em PCR e ao realizar as manobras mecânicas e farmacológicas empregadas no processo de reanimação cardiopulmonar e pós-reanimação de maneira sistemática e vertiginosa foi possível retirar a paciente do quadro de óbito iminente (FLETCHER et al., 2012).

A reanimação cardiopulmonar bem sucedida foi o primeiro passo a justificar a sobrevivência da paciente em questão, dado que, viabilizou a realização de manobras futuras de descontaminação, eliminação e tratamento de suporte e sintomático. Essas manobras, em associação, são cruciais para um bom desfecho de pacientes em quadros de intoxicações agudas (GLASS et al., 2019).

A desintoxicação e descontaminação da paciente foi inicialmente realizada de forma genérica, frente ao ineditismo do quadro de intoxicação por 5-FU para a equipe, com a manutenção da normovolemia e medidas que minimizem a absorção gastrointestinal do fármaco. No entanto, posteriormente foi potencializada por manobra de desintoxicação específica, a hiperventilação discreta assistida promovida pelo aquecimento monitorado da paciente. Esta manobra pode incrementar o metabolismo celular hepático e contribuir para desintoxicação mais rápida nos casos de ingestão de 5-FU, visto que, a droga é metabolizada pelo fígado e um dos seus subprodutos é o $\mathrm{CO}_{2}$ (EFUDEX, 2005).

O primeiro fármaco de escolha para controle de crises convulsivas de origens diversas em cães é o diazepam. No entanto, o diazepam é raramente eficaz como 
anticonvulsivante em casos de intoxicação por 5- FU. As crises convulsivas tônicoclônicas apresentadas pela paciente também foram refratárias aos bolus e infusão continua de diazepam o que corrobora com a literatura consultada (DORMAN et al.,1990).

Após 24 horas de internação sinais compatíveis com mucosite e gastroenterite foram observados, conforme observado por vários autores (DORMAN et al.,1990) sendo o tratamento de suporte realizado efetivo para tal. No que se diz respeito às amostras de sangue coletadas durante a admissão da paciente na UTI não foram observadas alterações em hemograma e maiores alterações em perfis hepáticos e renais.

\section{CONCLUSÃO}

O pronto serviço de terapia intensiva, ofertando manobras de reanimação, de desintoxicação, descontaminação e tratamento suporte e sintomático da paciente adequados e rápidos são essenciais nos quadros graves de intoxicação por 5-FU em cães e pode levar a sobrevivência do paciente em quadros considerados anteriormente pela literatura $100 \%$ letais como observado no presente trabalho.

\section{REFERENCIAS}

ASAD, U., BOOTHE, D., TARBOX, M. Effect of topical dermatologic medications in humans on household pets. Baylor University Medical Center Proceedings, v.33, n. $1, \quad$ p. $131-132, \quad 2020 . \quad$ Disponível em https://www.ncbi.nlm.nih.gov/pmc/articles/PMC6988634/pdf/ubmc-33-011679003.pdf. DOI 10.1080/08998280.2019.1679003. Acesso em 12/05/2020.

DIASIO, R.B.; HARRIS, B.E. Clinical pharmacology of 5-Fluorouracil. Clinical Pharmacokinetics, v.16, n.4, p.215-237,1989. Disponível em: <https://scihub.tw/https://doi.org/10.2165/00003088-198916040-00002> DOI: 10.2165/00003088-198916040-00002. Acesso em: 05/03/2020.DORMAN, D.C.; CODDINGTON,K. A; RICHARDSON, R.C. 5-Fluorouracil toxicosis in the dog. Journal of Veterinary, v.4, n.5, p. 254-257, 1990. Disponível em: https://onlinelibrary.wiley.com/doi/epdf/10.1111/j.1939-1676.1990.tb03118.x. DOI: 10.1111/j.1939-1676.1990.tb03118.x. Acesso em: 10/05/2020.

EFUDEX (fluorouracil): pomada. Responsável técnico Costa Mesa. California: Valeant Pharmaceuticals, 2005. Bula de Medicamento.

FLETCHER, D.J.; BOLLER, M.; BRAINARD, B.M., HASKINS, S.C., HOPPER, K; et al.. RECOVER evidence and knowledge gap analysis on veterinary CPR. Part 7: Clinical guidelines. Journal Veterinary Emergency and Critical Care Society, v.22, n.1, p.102-131, $2012 . \quad$ Disponível em: <https://onlinelibrary.wiley.com/doi/epdf/10.1111/j.1476-4431.2012.00757.x.> DOI: 10.1111/j.1476-4431.2012.00757.x. Acesso em: 10/05/2020.

FRIEDENBERG, S.G.; BROOKS, A.C.; MONNING, A.A.; COOPER, E.S. Successful tratament of a dog with massive 5- Fluorouracil toxicosis. Journal Veterinary Emergency and Critical Care, v.23, n.6, p. 643-647, 2013. Disponível em: https://sci-hub.tw/10.1111/vec.12116. DOI: 10.1111/vec.12116. Acesso em: 10/05/2020. 
GLASS E.N., SONG, R.B. KENT, M. Warning regarding 5-fluorouracil intoxication and calculation of dose exposure, Journal of Veterinary Emergency and Clinical Care. v 29, n 4, p. 450. DOI: 10.1111/vec.12849. 2019 Disponivel em https://onlinelibrary.wiley.com/doi/abs/10.1111/vec.12849. Acesso em: 10/05/2020.

KHOO, A.A., MULGREW, S, NORTON, S. A dog's life: an unfamiliar and lethal side effect of topical 5-fluorouracil, Clinical and Experimental Dermatology v 43, n. 6, p732 2018. Disponível em https://onlinelibrary.wiley.com/doi/abs/10.1111/ced.13537. DOI 10.1111/ced.13537. Acesso em 12/05/2020.

KOENIGSHOF, A.M.; BEAL, M.W.; POPPENGA, R.H.; JUTKOWITZ, A. Effect of sorbitol, single, and multidose activated charcoal administration on carprofen absorption following experimental overdose in dogs. Veterinary Emergency and Critical Care Society, v.25, n.5, p.606-610, 2015. Disponível em: <https://scihub.tw/10.1111/vec.12305>. DOl: 10.1111/vec.12305

LONGLEY, D.B.; HARKIN, D.P.;JOHNSTON, P.G. 5-Fluorouracil: mechanisms of action and clinical strategies. Nature Reviews Cancer, v.3, n.5, p.330-338, 2003. Disponível em: <https://sci-hub.tw/10.1038/nrc1074>.DOI: 10.1038/nrc1074 . Acesso em: 10/04/2020.

MENARD, K., BRIAN, K., GLAHN, A., BOUDREAUX, B., Concurrent 5-fluorouracil and carboplatin for the treatment of canine carcinomas. Veterinary and Comparative Oncology. v 16, s/n, p.90-595.2018. Disponível em https://onlinelibrary.wiley.com/doi/abs/10.1111/vco.12426. DOI: 10.1111/vco.12426 Acesso em 13/05/2020.

OVERTON T.L; ALLBAUGH R.A., WHITLEY D., BEN-SHLOMO G., et al. A pulsedose topical $1 \% 5$-fluorouracil treatment regimen in a young dog with corneal squamous cell carcinoma. Veterinary Ophatalmology, v. 18, n.4, p. 350-4. DOI 0.1111/vop.12220.2015 Disponivel em https://onlinelibrary.wiley.com/doi/abs/10.1111/vop.12220. Acesso 13/05/2020.

ROMANS, C. W., DAY, T. K., SMITH, J.J. Oxidative red blood cell damage associated with propofol and intravenous lipid emulsion therapy in a dog treated for 5-fluorouracil toxicosis. Journal of Veterinary Emergence and Clinical Care.v.1, $p$ 1-6 2020 Disponivel em https://onlinelibrary.wiley.com/doi/abs/10.1111/vec.12958. DOI: 10.1111/vec.12958. Acesso em 14/05/2020.

SAYRE, R.S.; BARR, J.W.; BAILEY, E.M. Accidental and experimentally induced 5fluorouracil toxicity in dogs. Journal of Veterinary Emergency and Critical Care, v. 22, n. 5, p. 545-549, 2012. Disponível em: < https://sci-hub.tw/10.1111/j.14764431.2012.00783.x > DOI: 10.1111/j.1476-4431.2012.00783.x Acesso em: 02/03/2020.

VELÁSQUEZ. J.C.; GONZÁLEZ.D.M.; PINILLA.P.A.; RODRIQUEZ.C.A. et al. Encefalopatía inducida por 5- Fluorouracilo. Um mismo agente, dos entidades diferentes. Acta Medica Colombiana, v.40, p-338-344, 2015. Disponível em: http://www.scielo.org.co/pdf/amc/v40n4/v40n4a12.pdf > . Acesso em: 10/05/2020.

ZHOU B., ZHANG D., PEI S. M. ZHANG H. et al. Establishment of 5-Fluorouracilresistant canine mammary tumor cell line. Polish Journal of Veterinary Sciences, v 28, n.20, p-103-110.. DOI 10.1515/pjvs-2017-0014. 2017 Disponivel em ENCICLOPÉDIA BIOSFERA, Centro Científico Conhecer - Goiânia, v.17 n.32; p. 356 2020 
https://onlinelibrary.wiley.com/doi/abs/10.1111/vop.12220. Acesso 13/05/2020.

ZHOU B., JIN Y., ZHANG D, LIN D. 5-Fluorouracil may enrich cancer stem cells in canine mammary tumor cells in vitro, Oncology Letters. v. 15, n. 5, p 7987-92,. DOI: 10.3892/ol.2018.8267. 2018 Disponível em https://www.ncbi.nlm.nih.gov/pmc/articles/PMC5943676/pdf/ol-15-05-7987.pdf. Acesso 13/05/2020. 